\title{
Onde ficam os pequenos enquanto os adultos participam de atividades políticas nos movimentos sociais?
}

\author{
Ticyane Madeira Cavalcanti \\ Assistente Social formada na Universidade Federal Fluminense. Mestranda em Educação na mesma instituição.
}

\begin{abstract}
Resumo
Neste trabalho pretendemos verificar a organização, registrar as atividades de uma política de gênero implementada nos espaços da CSP - Conlutas (Central Sindical e Popular). Sua existência está ligada aos princípios classistas sobre os quais se assenta esta organização. Surgiu com o intuito de aumentar a participação de mulheres no movimento social, de possibilitar sua organização permanente. Os dados, a observação e a analise comprovam sua importância e sua eficácia. Aporte teórico para os demais interessados em estudar o tema e/ou organizações que se propuserem a implementar política que possibilite maior participação política dos membros de uma mesma família..

Palavras chave: Movimentos Sociais, Educação Popular, Gênero, Família.
\end{abstract}

\section{Introdução}

O presente estudo se debruça sobre os espaços de recreação e cuidado criados para que fiquem os filhos/as de militantes engajados em sindicatos e movimentos sociais durante 0 período de militância destes. Pretendemos observar o seu funcionamento a partir de um estudo exploratório das reuniões da coordenação nacional da CSP - Conlutas. Trabalhamos com a hipótese de que tais espaços são fundamentais para aumentar a participação de ativistas com filhos pequenos e pretendemos investigar como este processo vem ocorrendo, atualmente, nas reuniões bimestrais da coordenação nacional da CSP- Conlutas nos estados de Minas Gerais, São Paulo e Rio de Janeiro.

Para tal análise consideramos necessário compreender o cenário em que esta organização surge e os pressupostos teóricos em que se apóia, posto que estes é que vão determinar a existência e a importância dada a estes espaços.

$\mathrm{O}$ recorte de nosso objeto tem por foco analisar o suporte que a organização dá as famílias com filhos, para viabilizar sua participação em seus fóruns e como se dão as relações familiares em meio a esse ambiente político sindical.

Tendo primeiramente pensado num debate sobre as relações de gênero e a participação feminina já encontramos inicialmente um bonito avanço no que diz respeito à divisão de tarefas dométicas com os homens nestas reuniões. Os encontramos assumindo o cuidado com as crianças, pois as levam consigo para suas reuniões. Mesmo considerando o impacto que esta ação provoca na vida das mulheres, não tendo entrevistado as mães e não podendo no espaço desta pesquisa ir adiante neste aspecto, nos deteremos sobre a questão da militância da maioria dos envolvidos (no caso homens, pais) e da relação entre estes, crianças e organização.

Mesmo considerando muito importante uma análise do contexto histórico que possibilita o nascimento da organização e das condições em que esta se constitui para que possamos entender como ela incorpora em seu programa as bandeiras feministas que vão ser a justificativa primeira para existência de tais espaços (dentre elas a luta por creches, inclusive nos espaços de militância) neste estudo _ em função do recorte que optamos por fazer neste momento_ não nos debruçaremos sobre estas questões, embora as tenhamos estudado quando da sua elaboração.

Neste estudo apresentaremos o relato da nossa experiência e observação. Buscaremos pensá-las comparando-a com experiências em curso em educação popular em outros movimentos sociais. Contribuiremos com os estudos sobre esta experiência incipiente e numa relação dialética contribuiremos com ela mesma através da reflexão sobre o que estes espaços aí representam e sobre o quanto pode avançar no sentido de melhor acolher estas crianças e melhor cumprir o papel fundamental que cumpre dentro de uma organização que se revela fundamental na disputa por um projeto societário que efetivamente emancipe a classe trabalhadora.

\section{Método}

O trabalho trata-se de uma pesquisa do tipo descritiva. De acordo com Gil (2006), as pesquisas que se enquadram nesse tipo objetivam, primordialmente, "a descrição das características de determinada população, fenômeno ou o estabelecimento de reações entre variável”.

A aplicação de questionário semi - aberto e a entrevista no local onde estavam acontecendo as atividades possibilitou que os entrevistados refletissem e também observassem aspectos sobre os quais ainda não haviam refletido sobre a organização do espaço onde ficam as crianças.

Complementando, Minayo (2003) diz que, a abordagem qualitativa releva-se por ser compreendida enquanto aquela apta a incorporar questões do significado/intencionalidade como próprios dos atos, às relações, bem como das estruturas sociais, sendo essas 
últimas aceitas como construções humanas significativas.

O autor aponta ainda que a pesquisa qualitativa se preocupa nas ciências sociais com um nível de validade que não pode ser quantificado, posto que a mesma trabalha com o universo de significados/motivos/aspirações/crenças/valores/atitudes , equivalendo a um espaço mais denso das relações dos métodos e dos fatos que não podem ser restringidos à operacionalização de variáveis (MINAYO, 2003).

Trata-se de pesquisa qualitativa, utilizando entrevistas com perguntas abertas para coleta de dados.

Com a finalidade de examinar as respostas à entrevista acerca das questões relativas a sua militância na CSP Conlutas, tornando possível estabelecer a análise de conteúdo, que segundo Chizzotti (2006), seria:

Um método de tratamento e análise de informações, colhidas por meio de técnicas de coleta de dados, consubstanciadas em um documento. A técnica se aplica à análise de textos escritos ou de qualquer comunicação (oral, visual, gestual) reduzida a um texto ou documento. (CHIZZOTTI, 2006)

Essa pesquisa ocorre em três fases. Primeiro a pesquisa se dá em material bibliográfico para apoio na realização das entrevistas. No segundo momento os dados coletados. Num terceiro momento há um retorno a pesquisa bibliográfica, a análise dos dados coletados e também a redação do texto final.

\section{Participantes}

O público alvo desse estudo é constituído por quatro adultos na faixa etária de 19 a 60 anos, de ambos os sexos, militantes da CSP - Conlutas que estavam presentes em duas reuniões da coordenação nacional da central, nos dias 5, 6 e 7 de julho de 2013 em São Paulo SP e nos dias 27, 28 e 29 de setembro do mesmo ano no Rio de Janeiro.

Cabe dizer que, o sigilo dos sujeitos participantes será mantido, tendendo protegê-los de quaisquer implicações legais, advindas da pesquisa. Os dados coletados serão utilizados neste estudo como fontes primárias, sendo destruídos oportunamente. Assim sendo, a privacidade dos sujeitos será mantida, em obediência do Código de Ética dos Assistentes Sociais.

Cada sujeito participante ficou esclarecido individualmente acerca da natureza da pesquisa; participação voluntária, garantia da confidencialidade das informações, assim como seu anonimato; disponibilidade da entrevista para a guarda/destruição em caso de desistência.

\section{Instrumentos}

Foram realizadas entrevistas com quatro militantes da organização responsáveis por sete crianças. Cinco destas crianças estavam na reunião em São Paulo (sendo três moradoras da cidade onde se dava a reunião, uma do interior deste mesmo estado e a outra de Minas Gerais) e outras duas observadas na reunião no Rio de Janeiro eram de Minas Gerais.
Os pais não ofereceram qualquer resistência a participação na pesquisa, assim como autorizaram com muita boa vontade a entrevista com as crianças e também o uso da sua imagem e voz durante a elaboração e apresentação deste trabalho.

Com os trabalhadores responsáveis pelo espaço conversei informalmente, embora tenham disso avisadas desde o ingresso no local a razão de eu estar ali acompanhando suas atividades. Durante a realização das mesmas procurei ajudar em uma coisa ou outra e conversando com elas e com as crianças e assim obtivemos muitas informações. Tivemos o uso da sua imagem também autorizada, mas por estarem no exercício de suas funções não tive oportunidade de fazer com elas entrevista mais demorada ou mesmo gravar a conversa que tive com as mesmas.

Da mesma forma se deram conversas com a responsável pela organização do espaço que nos dois momentos (reunião da coordenação nacional em São Paulo e Rio de Janeiro). Ela demonstrou a mesma disponibilidade e boa vontade que os responsáveis e trabalhadoras do local. Horas antes, durante e depois da realização da atividade os responsáveis pela organização estão muito envolvidos com o trabalho na estrutura do evento de modo que não teriam como parar as suas atividades para realizar entrevista gravada para posterior transcrição. Conversas se deram desde antes e o contato com eles continuou posteriormente por correio eletrônico, telefone e em outros fóruns onde nos encontramos e todas as dúvidas a respeito do espaço foram prontamente sanadas.

\section{Resultados}

O movimento de mulheres, classista, existente dentro da central desde a sua fundação defende a importância da existência de tais espaços para a participação política das mulheres. No entanto no curso das entrevistas e observações não é sem muita felicidade que pudemos constatar que a maioria dos presentes com crianças nas atividades eram os homens por elas responsáveis. Se por um lado isso expressa que a direção da central ainda é majoritariamente ocupada por homens, por outro estes homens tem assumido a responsabilidade do cuidado com as crianças de suas famílias, o que permite que as mães/tias/avós destas crianças possam estar neste momento se dedicando a outras atividades em militância, trabalho, estudos ou lazer e representa de algum modo um avanço na consciência destes e uma re - significação dos papéis historicamente atribuídos a cada um deles (homens e mulheres).

\section{Sobre as famílias militantes}

É fato que as mulheres/mães/avós/tias normalmente são as principais responsáveis pelos cuidados para com as crianças. Mesmo as profissões que envolvem a dimensão do cuidado, assim como a Educação ou a Enfermagem, que exigem além da técnica sensibilidade e afeto, são notadamente setores com muito mais mulheres empregadas.

No entanto encontramos estudiosos que afirmam sobre outros estudos que "todos eles reconhecem que as 
práticas do cuidado devem ser compreendidas dentro de contextos específicos a cada grupo, considerando-se o momento histórico" (ACOSTA ; VITALE, 2010)

Assim no ambiente onde se desenvolve esta pesquisa foi muito comum encontrar homens desempenhando este papel. Isto está ligado ao patamar em que se encontra o debate na Central, a efetiva militância das mulheres em seus fóruns e de acordo com os princípios que reivindica.

Em outras palavras:

“ Ao falarmos do cuidado na relação com os filhos, dentro do debate do feminismo, do gênero e do estudos sobre os homens e as masculinidades, é importante situar a própria estrutura familiar num contexto histórico e social, pensando assim nas diversas formas que as relações de gênero ai se processam e como a paternidade foi exercida em diferentes momentos históricos. Vera Regina Ramires (1997) ressalta a importância da influencia dos meios de subsistência na estruturação das família e, consequentemente, no arranjo dos micro e macro poderes bem como dos papéis intra e extra familiares nas relações de gênero" (ACOSTA ; VITALE, 2010).

Causa $=$ nos felicidade encontrar homens que se deslocam de seus Estados com suas crianças e sem as suas companheiras e é notável a tranquilidade e a felicidade em suas faces no desempenho de suas atribuições.

Além de ajudar na exploração de toda a classe, quando 'impede” o desenvolvimento deste laço, o machismo retira dos homens tudo de bom que ele também proporciona.

"O poder social dado aos homens possui então uma dupla face, pois ainda que seja fonte de privilégios e poderes individuais, é também fonte de sofrimento, dor e alienação _ a alienação de seus sentimentos, de seus afetos, de um potencial para estabelecer sentimentos humanos de cuidado para com os filhos_visto que essa capacidade está "naturalmente" reservada as mulheres (LYRA, apud ACOSTA ; VITALE, 2010)

Foram entrevistados, em duas reuniões, três homens e uma mulher.

A mulher entrou para o Movimento Popular recentemente e estava na Reunião com seu companheiro e seus dois filhos. Os homens estavam sozinhos. Dois casados e o outro separado. Um dos casados é casado com outro homem.

São formatos de família diversos.

"Felizmente, para uma perspectiva ética que valoriza a flexibilidade e uma abertura para o novo, as pessoas não internalizam os atributos de gênero e os modelos hegemônicos como uma produção em série. O modelo hegemônico tem como principal função ser referencial na construção destas identidades" (ACOSTA ; VITALE, 2010).

E em todas as entrevistas os responsáveis responderam que os cuidados com as crianças no seu cotidiano são compartilhados com diversas pessoas e não há a responsabilização das mulheres exclusivamente em suas famílias. Se por um lado o padrão não é hegemônico, isto sim representa uma quebra de paradigma e "Essa quebra promoveria, portanto, uma mudança revolucionária na história da humanidade, quando o eixo do cuidado com os filhos começaria a fazer parte da subjetividade masculina“ (ACOSTA ; VITALE, 2010).

Um dos pais possui a guarda de fato de 3 crianças e a guarda jurídica é compartilhada com a mãe. A mãe paga pensão aos filhos e as crianças parecem bastante saudáveis e felizes.

"Não que haja uma inversão de papéis ou que o pai se transforme em outra mãe; trata-se de um homem - pai que estabelece relações mais complexas, estreitas e mais "reais" com os (as) filhos (as), que deseja e encontra grande satisfação com isso" (ACOSTA ; VITALE, 2010).

\section{Avaliação dos responsáveis}

Sobre a importância e necessidade do espaço há consenso entre todos os responsáveis. Nenhum dos entrevistados reclamou da dificuldade de militar levando crianças consigo e nenhum deles disse sofrer pressões familiares por fazerem isto.

Um dos entrevistados acredita que os espaços podiam funcionar muito melhor e atribui a sua qualidade ao profissional contratado para trabalhar diretamente com as crianças em cada momento/lugar, pois a sua filha às vezes deixa de ir para atividades programadas com seus amigos ou familiares para ir para as reuniões se uma determinada pessoa de quem ela gosta muito e com quem já estabeleceu uma relação tiver sido contratada para ficar com as crianças neste momento.

Os demais nunca haviam problematizado o espaço e tiveram até alguma dificuldade responder perguntas sobre ele, pois embora sejam enfáticos sobre sua necessidade e importancia, não haviam parado para observar e refletir sobre as suas diversas características em nenhum momento.

\section{O que observamos das crianças}

Em ambos os espaços as crianças pareceram bem. Estavam felizes. Brincavam, faziam desenhos, circulavam. Algumas não sabiam onde estavam exatamente ou o que estariam fazendo ali ou por serem muito pequenas ou porque não se conversou com elas sobre isso. Parte das crianças sabia o que estava fazendo lá e considerava a militância dos responsáveis muito importante e se sentiam parte dela.

\section{Discussão}

Sendo este tema muito extenso e de difícil acesso a bibliografia sobre ele, esse trabalho não pretendeu em nenhum momento dar conta da totalidade desta questão, mas somente iniciar um estudo sobre as crianças que deambulam nos movimentos sociais e a eles conferem ainda mais graça e cor.

A família é alvo de políticas no atual estágio do capitalismo.

Em outras palabras, ou mais profundamente 
“ Neste contexto, o Estado, isentando-se dos deveres de prover o cuidado dos cidadãos, sobrecarrega a família, conclamando-a a ser parceira da escola e das políticas públicas, e a sociedade, atônita, na ausência de lugares "com calor, elege-a como lugar da proteção social e psicológica” (ACOSTA ; VITALE, 2010)

É também espaço de acolhimento, amor, disputas, reprodução material e ideológica. É preciso pensar sobre ela em todos os seus formatos. E lhe conferir assistência.

Se nesse momento é alvo de políticas focais é só porque ainda serve aos interesses capitalistas e o seu formato sofre intervenção todo tempo ao longo da história também em função disto.

Assim concordamos com autores que proponham

"o trabalho socioeducativo e militante, que adota a família como locus do protagonismo social para usar o feitiço contra o feiticeiro, ir na contra corrente do biopoder, usando o mesmo remédio para obter efeitos contrários: em lugar da disciplinarização, a liberdade; em lugar do isolamento a abertura ao coletivo" (ACOSTA ; VITALE, 2010)

As crianças estão no movimento desde sempre. Com suas mães, com suas tias, suas avós e também com os seus pais. Manter espaços onde elas possam ser acolhidas é fundamental para o exercício de militância dos seus responsáveis e deste modo para a luta pela destruição deste modo de produção e a construção de uma nova sociedade. A participação das crianças e o seu olhar sobre o movimento faz parte de um movimento dialético de educação delas mesmas e de todos que se entrecruzam nesta caminhada.

Como

“ Há uma associação direta entre praticas socializadoras (ou educativas) de crianças e jovens e as concepções de desenvolvimento humano em que elas se baseiam. O que acontece, na maioria das vezes, ou é uma mera repetição da tradição ou uma reprodução irrefletida de práticas que trazem embutidas concepções de desenvolvimento que podem não ser adequadas para aqueles a quem se destinam." (ACOSTA ; VITALE, 2010)

Se sob alguns aspectos a não funcionam como poderiam precisamos refletir e incorporar experiências no sentido de fortalecer este projeto.

No curso desta pesquisa e considerando toda experiência na militância foi elaborado um projeto de intervenção a ser implementado nos fóruns da instituição.

É uma contribuição do Serviço Social a ser implementada em colaboração com outros profissionais pois

“ Falar em desenvolvimento humano deixou de ser uma atividade restrita a uma profissão ou especialidade. Trata-se de considerar esse fenômeno em sua dimensão histórica, social, antropológica, educacional, psicológica e política e política, pois se está lidando com concepções de seres humanos e se pensando em estratégias para dar continuidade às sociedades e as culturas” (ACOSTA ; VITALE, 2010)

Como

“É importante a manutenção de uma atitude crítica em relação as propostas de universalização e uniformização de um processo multifacetado, que, se de um lado compartilha semelhanças, de outros se diferencia nas diferentes culturas e camadas sociais, parte que é do complexo fenômeno humano. ” (ACOSTA ; VITALE, 2010)

Este projeto não tem a intenção de uniformizar os espaços, é para ser discutido e reelaborado quantas vezes forem necessárias de acordo com a quantidade de tempo de duração, a faixa etária das crianças atendidas, a região onde será realizado o evento e quaisquer outros fatores que possam gerar necessidades específicas.

Ao longo da minha caminhada lutei para que existissem estes espaços, eu os utilizei muitas vezes, lá deixei minha filha. Pensei nos problemas e possibilidades desse espaço e o revisitei. Defendo intransigentemente a sua existência e trabalharei com todas as minhas forças para aprimorá-los, pois ele é fundamental para nossas crianças e nós mesmas pois de acordo com a sua qualidade podemos estar mais tranquilas enquanto nos organizamos para que a riqueza socialmente produzida também seja socialmente apropriada.

\section{Referencias}

ACOSTA, Ana Rojas; VITALE, Maria Amalia Faller. Família: Redes, laços e políticas públicas. São Paulo: Cortez, 2010.

ARENHART, Deise. Infância, Educação e MST: quando as crianças ocupam a cena. Chapecó: Argos, 2007.

ARIÈS, Philippe. História social da criança e da família. Rio de Janeiro: Zahar Editores, 1978.

BOURDIEU, Pierre. A dominação masculina. Rio de Janeiro: Bertrand Brasil, 1999.

Brasil, 2007.

O poder simbólico. Rio de Janeiro: Bertrand

CHIZZOTTI, Antonio. Pesquisa qualitativa em ciências humanas e sociais. Petrópolis: Vozes, 2006

CIVILETTI, M.V. O cuidado das crianças pequenas no Brasil Escravista - Cadernos de Pesquisa SP n. 76. P. 31-40

DA MATTA, Roberto. A casa e a rua. Espaço, cidadania, mulher e morte no Brasil. São Paulo: Brasiliense, 1985.

ENGELS, Friedrich. A origem da família, da propriedade privada e do Estado. São Paulo: Escala.

LOBO, Elizabeth Souza. A classe operária tem dois sexos: trabalho, dominação e resistência. São Paulo: Editora Fundação Perseu Abramo, 2011.

MINAYO, Maria Cecília de Souza. O desafio do conhecimento científico: pesquisa qualitativa em saúde. $5^{\mathrm{a}}$ ed. São Paulo/Rio de Janeiro: Hucitec-Abrasco, 2003. 
NIDELCOFF, Maria Teresa. Uma escola para o povo. São Paulo Editora Brasiliense, 1980.

PAOLI. M. Celia. A familia operária. Notas sobre sua formação histórica no brasil . Tempo Social. Revista de Sociologia da USP. Vo 4 1-2 p. 17-41, jan- jun 1994

PETIT, Mercedes; CARRASCO, Carmem. Mulheres trabalhadoras e marxismo. Um debate sobre opressão. São Paulo: Editora Instituto José Luís e Rosa Sudermann, 2012.

SARTI, Cynthia Andersen. A família como espelho: um estudo sobre a moral dos pobres. São Paulo: Autores Associados, 1996.
SAYS, Sharon. Contradições culturais da maternidade. Rio de Janeiro: Gryphus, 1998.

TOLEDO, Cecília. O Gênero nos une, a classe nos divide. São Paulo: Sudermann, 2008.

TROTSKY, Leon. Questões do modo de vida. A moral deles e a nossa. São Paulo: Editora Instituto José Luís e Rosa Sudermann, 2009.

VENDRAMINI, Celia Regina; MACHADO, Ilma Ferreira. Escola e movimento social: experiências em curso no campo brasileiro. São Paulo: Expressão Popular, 2011. 